\title{
Pyramidal and Proprioceptive Dysfunctions as the Main Neurologic Features In Symptomatic Type I Chiari Malformation Patients
}

\section{Disfunções piramidais e proprioceptivas como principais alterações neurológicas em pacientes sintomáticos portadores de malformaçõo de Chiari tipo I}

Bruno Corrêa de Albuquerque Leimig ${ }^{1}$ Claudio Henrique Fernandes Vidal ${ }^{2}$ Marcelo Moraes Valença ${ }^{2}$ Joacil Carlos da Silva ${ }^{2}$ Walter de Freitas Matias Filho ${ }^{2}$

1 Hospital Estadual Getulio Vargas, Recife, PE, Brazil

2 Universidade Federal de Pernambuco, Recife, PE, Brazil

Address for correspondence Bruno Corrêa de Albuquerque Leimig, MD, Hospital Estadual Getulio Vargas, Recife-PE,

Arq Bras Neurocir 2018;37:258-262. Recife, PE, Brazil (e-mail: bleimig@gmail.com).

\begin{abstract}
Keywords

- arnold-chiari malformation

- neurologic examination

- pyramidal tracts

- proprioception

- syringomyelia
\end{abstract}

\section{Resumo}

Objective Broader access to magnetic resonance imaging (MRI) has increased the diagnosis of tonsillar ectopia, with most of these patients being asymptomatic. The early diagnosis and treatment of type I Chiari malformation (CM I) patients has impact on the prognosis. This study supplements information about the neurologic exam of symptomatic patients with CM I.

Methods The sample was composed of 32 symptomatic patients with CM I diagnosed by a combination of tonsil herniation of more than $5 \mathrm{~mm}$ below the magnum foramen (observed in the sagittal T2 MRI) and at least one of the following alterations: intractable occipital headache, ataxia, upper or lower motor neuron impairment, sensitivity deficits (superficial and deep) or lower cranial nerves disorders.

Results Occipital headache was the most frequent symptom (53.12\%). During the physical exam, the most common dysfunctions were those from the pyramidal system (96.87\%), followed by posterior cord syndrome (87.5\%).

Discussion In this study, patients became symptomatic around the fifth decade of life, which is compatible with previous descriptions. Patients with more than 2 years of evolution have worse responses to treatment. Occipital headache, symptoms in the upper limbs, gait and proprioceptive disorders are common findings in patients with CM I.

Conclusion Deep tendinous reflexes and proprioception disorders were the main neurologic features found in symptomatic CM I patients.

Objetivo O acesso amplo à ressonância magnética (RM) vem aumentando o diagnóstico de ectopia tonsilar, sendo a maioria dos pacientes com essa condição assintomáticos. O diagnóstico precoce e tratamento dos pacientes portadores da received

April 6, 2018

accepted after revision

June 27, 2018

published online

September 27, 2018
DOI https://doi.org/

$10.1055 / \mathrm{s}-0038-1670696$.

ISSN 0103-5355.
Copyright @ 2018 by Thieme Revinter

Publicações Ltda, Rio de Janeiro, Brazil
License terms

(c) $(1) \$$ 
Palavras-chave

- malformação de Arnold-Chiari

- exame neurológico

- tratos piramidais

- propriocepção

- Siringomielia malformação de Chiari tipo I (MC I) tem impacto no prognóstico. O presente estudo adiciona informações sobre o exame neurológico dos pacientes com MCI sintomáticos. Métodos A amostra foi composta por 32 pacientes sintomáticos com MC I diagnosticados por herniação tonsilar maior que $5 \mathrm{~mm}$ abaixo do forame magno (constatada na sequência sagital-T2 da RM) e uma das alterações a seguir: cefaleia occipital intratável, ataxia, disfunção do neurônio motor superior ou inferior, déficit sensitivo (superficial e profundo) ou paresia de nervos cranianos baixos.

Resultados A cefaleia occipital foi o sintoma mais prevalente $(51,12 \%)$. Durante o exame físico, a disfunção mais comum foi da via piramidal $(96,87 \%)$, seguida de síndrome cordonal posterior (87,5\%).

Discussão No presente estudo, os pacientes se tornaram sintomáticos por cerca da quinta década de vida, compatível com as descrições prévias. Pacientes com mais de 2 anos de evolução obtiveram pior resposta ao tratamento. Cefaleia occipital, sintomas nos membros superiores, distúrbios de marcha e propriocepção são achados frequentes em pacientes com MC I.

Conclusão Reflexos tendinosos profundos e alteração da propriocepção são os os principais sinais no exame neurológico dos pacientes com MC I.

\section{Introduction}

Tonsillar ectopia, the sine qua non anatomopathological criterion of type I Chiari malformation (CM I), may be understood as a disproportion between the cranial vault and its content, that is, the nervous tissue. ${ }^{1}$ This may be due to the underdevelopment of occipital somites, from the paraxial mesoderm. As a result, a small posterior fossa is developed predisposing to a downward herniation of its contents, that is, cerebellar tonsils migrating to the cervical spinal canal. ${ }^{1,2}$

The prevalence of MRI-diagnosed CM I is reported to be between 0.56 and $0.77 \%{ }^{3,4}$ Symptoms usually begin in the second and third decades of life. ${ }^{5}$ Adults with CM I are frequently asymptomatic for years. ${ }^{6,7}$ Early diagnosis and treatment of CM I patients have an impact on the prognosis. ${ }^{8}$ Nowadays, broader access to MRI has increased the diagnosis of asymptomatic or oligosymptomatic patients with CM I. ${ }^{9}$

The clinical features of CM I are widely described; however, few studies have statistically quantified symptoms and signs found in neurological exam. ${ }^{10}$ There is no mention in their review regarding the frequency of neurologic impairment (long tracts and lower cranial nerves).

The present study compares clinical data from the neurologic examination of symptomatic patients with CM I to information previously described in the literature and informs the percentage of altered features in their exam.

\section{Methods}

A neurological exam was performed in all 32 patients by a single examiner from March 2010 to June 2014 at hospital admission, before surgical planning. Clinical data was afterwards evaluated and compiled in - Tables 1-4

The study protocol was approved by the institutional review board of the participating center (CAAE:
Table 1 Symptoms observed in the 32 type 1 Chiari malformation patients, showing absolute and relative frequencies

\begin{tabular}{|l|l|l|}
\hline Symptoms & N & \% \\
\hline Occipital headache & 17 & 53.12 \\
\hline Diplopia & 7 & 21.87 \\
\hline Dizziness & 8 & 25 \\
\hline Dysphagia & 8 & 25 \\
\hline Gait disorders & 11 & 34.37 \\
\hline Sphincter disorders & 3 & 9.37 \\
\hline Weakness in upper limbs & 11 & 34.37 \\
\hline
\end{tabular}

Table 2 Absolute and relative frequencies of signs categorized by systems, observed during the physical examination

\begin{tabular}{|l|l|l|}
\hline Signs & N & $\%$ \\
\hline Ophthalmoparesis & 2 & 6.25 \\
\hline Nystagmus & 6 & 18.75 \\
\hline $5^{\text {th }}$ nerve palsy & 4 & 12.5 \\
\hline $9^{\text {th }} / 10^{\text {th }}$ nerve palsy & 15 & 46.87 \\
\hline $11^{\text {th }}$ nerve palsy & 1 & 3.12 \\
\hline Axial ataxia & 6 & 18.75 \\
\hline Appendicular ataxia & 14 & 43.75 \\
\hline Cordonal posterior disorder & 28 & 87.5 \\
\hline Tactile sensibility disorder & 11 & 34.37 \\
\hline Pain sensibility disorder & 16 & 50 \\
\hline Pyramidal syndrome & 31 & 96.87 \\
\hline Lower motor neuron syndrome & 14 & 43.75 \\
\hline
\end{tabular}


Table 3 Absolute and relative frequencies of motor signs in type 1 Chiari malformation patients

\begin{tabular}{|l|l|l|}
\hline Motor exam & N & \% \\
\hline Hyperreflexia & 31 & 96.87 \\
\hline Lower limbs alone & 12 & 37.5 \\
\hline All four limbs & 19 & 59.37 \\
\hline Motor deficit & 1 & \\
\hline Brachial monoparesis & 1 & 3.12 \\
\hline Crural monoparesis & 6 & 18.75 \\
\hline Brachial biparesis & 14 & 43.75 \\
\hline Cruciate paralysis & 1 & 3.12 \\
\hline Hemiparesis & 6 & 18.75 \\
\hline Tetraparesis & 2 & 6.25 \\
\hline Other signals & & \\
\hline Hoffmann & 9 & 28.12 \\
\hline Babinski & 8 & 25 \\
\hline
\end{tabular}

0329.0.172.000-09), and all patients gave written consent for data analysis. It was a sectional and descriptive evaluation in a surgical series of cases. The sample comprised symptomatic patients with CM I who were submitted to surgical interventions after their diagnosis to prevent evolution of the disease.

The inclusion criteria were patients with tonsils more than $5 \mathrm{~mm}$ below the foramen magnum (observed on sagittal T2 MRI) and at least one of the following situations: 1) intractable occipital headache worsened by Valsalva maneuver (suggestive of dysfunctional cerebrospinal fluid circulation), 2) ataxia, 3) upper and lower motor neuron dysfunction, 4) sensitivity deficits (superficial and deep), 5) lower cranial nerves disorders (particularly swallowing and speaking). Patients with CM I plus syringomyelia were also included, but all patients with significant subluxation of the axis or other ventral compressions were excluded.

Neurological exams were performed by a single neurosurgeon in all patients.

\section{Results}

Thirty-two patients, 15 (46.87\%) men and 17 (53.12\%) women were evaluated from March 2010 to June 2014. The minimum and maximum ages were 16 and 53 years, respectively, with a mean of $39.62 \pm 10.12$ years. The mean duration of symptoms was $56 \pm 46$ months (minimum of 3 and maximum of 180 months). Data from the anamnesis are shown in -Table 1.

Occipital headache was the most prevalent symptom, worsened during Valsalva's maneuver in 10 patients (31.25\%). Absolute and relative frequencies of signs are shown in -Table 2.

Pyramidal system dysfunctions were the most prevalent finding, with hyperreflexia being the most common sign on physical examination. Pyramidal disorders were followed by posterior cord disorders. (see - Table $\mathbf{3}$ ).
Table 4 Absolute and relative frequencies of sensorial deficits in type 1 Chiari malformation patients

\begin{tabular}{|l|l|l|}
\hline Sensitivity Deficits & N & $\%$ \\
\hline Tactile & 11 & 34.37 \\
\hline Brachial unilateral & 6 & 18.75 \\
\hline Half body & 3 & 9.37 \\
\hline Crural unilateral & 1 & 3.12 \\
\hline Hemithorax & 1 & 3.12 \\
\hline Nociceptive & 16 & 50 \\
\hline Uni or bibrachial & 10 & 31.25 \\
\hline Half body & 5 & 15.62 \\
\hline Hemithorax & 1 & 3.12 \\
\hline Pain and tactile dissociation & 6 & 18.75 \\
\hline Sense of position (proprioception) & 23 & 71.87 \\
\hline Brachial unilateral & 3 & 9.37 \\
\hline Crural unilateral & 3 & 9.37 \\
\hline Lower limbs & 5 & 15.62 \\
\hline Half Body & 1 & 3.12 \\
\hline 3 limbs & 5 & 15.62 \\
\hline 4 limbs & 6 & 18.75 \\
\hline Vibratory sensation & 26 & 81.25 \\
\hline Brachial unilateral & 4 & 12.5 \\
\hline Crural unilateral & 7 & 21.87 \\
\hline Upper limbs & 1 & 3.12 \\
\hline Lower limbs & 8 & 25 \\
\hline 3 limbs & 2 & 6.25 \\
\hline 4 limbs & 4 & 12.5 \\
\hline & & \\
\hline & 6 \\
\hline
\end{tabular}

Motor deficit of the upper limbs associated with clinical signs of syringomyelia (intrinsic hand muscle atrophy and pain-touch dissociation) was found in 14 (43.75\%) patients, while paresis in one of the upper limbs with no signs of syringomyelia was observed in just 1 (3.12\%) patient. The data from the sensorial examination are shown in - Table 4.

Six patients (18.75\%) presented the classic pain-touch dissociation, with preservation of touch sensitivity and decrease in pain sensation. The opposite situation was observed in just one patient.

\section{Discussion}

In this study, patients became symptomatic around the fifth decade of life, which is compatible with previous descriptions. ${ }^{6,11}$ Bejjani described as many as five years of delay to diagnose CM I. ${ }^{4}$ Patients with more than 2 years of evolution have worse responses to treatment because a long-term compression leads to arachnoid fibrosis that will not let this membrane expand after surgical decompression. ${ }^{8}$

The majority of patients were female (53.12\%), in the present series. Bejjani described a 3:1 female to male in their review. ${ }^{4}$ There is no clear explanation for this difference. 
Occipital headache was the most prevalent symptom (53.12\%), although only $31.25 \%$ referred worsening of headache after Valsalva maneuver. Headache is also the most common symptom described in the literature, ranging from 15 to $75 \%$ of patients. ${ }^{4-6,12}$ This typical topography may be related to compression of $\mathrm{C} 1$ and $\mathrm{C} 2$ roots by the herniated tonsils. ${ }^{2}$ It is usually described as a pressure-like pain, often felt at the neck, shoulder or retro-orbital regions. ${ }^{4}$ On the other hand, some patients experience severe headaches, despite the minimal tonsil ectopy. McGirt et al related the presence of occipital headache with blocking alterations during cerebrospinal fluid (CSF) circulation at the craniovertebral junction (CVJ), evaluated by cine-MRI. ${ }^{13}$ The worsening caused by Valsalva maneuver may be explained by both mechanisms.

Symptoms related to the upper limbs were presented by 11 (34.37\%) patients, and represented, along with gait disorder, the 2nd most common symptom. Another series describes it in $50 \%$ of the patients. ${ }^{14}$ This difference is possibly due to the fact that other series focused on syringomyelic patients, whereas the present study, also considers patients with CM I alone. Gait disorders could be explained by cerebellar, sensitive or pyramidal abnormalities.

From a syndromic perspective, pyramidal system dysfunctions were the most frequent and hyperreflexia was the most common clinical sign, previously mentioned by Saez et al. ${ }^{15}$ Voluntary motor disorders were the most common sign in the Silva study, present in $83 \%$ of patients. ${ }^{12}$ Paretic lower limbs were the most common presentation (66.2\%). In the current series, motor deficits were present in 25 (78.12\%) patients. It is difficult to be sure whether the motor deficits are caused by pyramidal tract disorders or motoneurons dysfunction, since the majority of the patients with CM I also have syringomyelia. In contrast, upper limbs deficit associated with signs of syringomyelia (thermic and pain dissociation, hand muscle atrophy) were present in 14 (43.75\%) patients. In this scenario, it is proper to attribute this deficit to motoneuron dysfunction.

Light touch deficits were observed in 11 (34.37\%) patients, 6 of which presented the unilateral brachial form (54.54\%). Only one, however, had a visible syringomyelic cavity on MRI. Pain hypoesthesia was present in 16 (50\%) patients, with upper limbs involvement in 10 (31.25\%) of them. Only two patients did not exhibit syringomyelic cavities on MRI studies, supporting the association between these cavities and nociceptive dysfunction.

Among all patients, only 6 (18.75\%) presented the classic pain-touch dissociation, with preservation of touch sensibility and decrease of pain sensation. The opposite situation was observed in just one patient. Mauer et al described the classic pain-touch dissociation in $15 \%$ of their patients. ${ }^{16}$ The diffusion of MRI facilities around the world could lead to early diagnosis of syringomyelia, preventing the development of its classical manifestations.

During deep sensitivity evaluation, segmental notion position and vibratory sensitivity dysfunctions were present in 23 (71.87\%) and 26 (81.25\%) patients, respectively. Twenty-nine (90.62\%) patients presented at least 1 of these posterior cord disorders. Only two patients with these dysfunctions did not show syringomyelic cavities on MRI studies. The preferential setting of painless disorders at upper limbs and proprioception dysfunctions at lower limbs, as described by Saez et al, was also found in the present series. ${ }^{15}$

Gilman stated that deep sensitivity is carried on the dorsolateral portions of the spinal cord, being spared in conditions that affect exclusively the posterior columns. ${ }^{17}$ Calne and Pallis emphasize the high frequency of dissociation between these two modalities of deep sensibility and questioned the existence of vibratory modality regarding its specificity of stimulus and afferent pathways, saying that it is carried by lateral portions of the spinal cord near the corticospinal tract. ${ }^{18}$ This statement was also defended by Netsky, who considers the vibratory sense as a modality of touch sensibility carried by multiple pathways. ${ }^{19}$ In the present study, vibratory-positional sensibility dissociation is present in nine $(28.12 \%)$ patients. Six $(18.75 \%)$ patients had pallesthesia deficits with bathyesthesia preservation. Three (9.37\%) patients had the opposite situation.

One patient had no signs of syringomyelia on the MRI; nevertheless, he had motoneuron dysfunction. This may be explained by vascular compression of the spinal cord at the level of the second vertebrae. Veins are easily collapsible because of their thin walls and low intravascular pressure. ${ }^{20}$ At the second cervical vertebra, just one dorsal vein has been described. ${ }^{21}$ It drains all cervical gray matter and ascends, leaving the neuroaxis at this level, transposing the duramater. ${ }^{22}$ Compression of CVJ compromises this drainage system, creating a retrograde dilation up to the precapillary system with stasis of the anterior and posterior spinal horns. ${ }^{22}$ As a result, micro-bleeding can occur from C5 to $\mathrm{T} 2$, with greater incidence at $\mathrm{C} 7$ and $\mathrm{C} 8 .^{22}$ It usually involves the central and posterior portions of the spinal cord. ${ }^{23}$

Necropsy studies in syringomyelic patients describe areas of gliosis in both white and gray matter, characterized by rare and hypertrophic astrocytes, compatible with chronic swelling. ${ }^{24}$ This swollen area is caused by reduction in venous draining at the CVJ, creating an additional obstacle to arterial inflow and venous drainage of the anterior and lateral portions of the spinal cord. ${ }^{25}$ These spinal cord regions are highly vulnerable to hipoperfusion. ${ }^{25}$ This venous underdrainage mechanism together with CSF flow obstruction may be crucial to the development of syringomyelia. ${ }^{26}$ Alternative routes to CSF in subarachnoid space are: the interstitial perivascular and perineural spaces; absorption by gray matter capillaries; its cranial drainage by the central medullary channel into the fourth ventricle. In case of obstruction of CVJ, both the subarachnoid route and the alternative paths for CSF are obstructed, leading to accumulation of liquid inside the spinal cord. ${ }^{24}$

Silva et al described a spastic-ataxic syndrome, as the main neurological finding in MC I and basilar impression patients, with special emphasis on pyramidal system and proprioception impairment. ${ }^{27}$ In the peripheral nervous system, thicker neurons are more susceptible to hypoxic events than fibers of small caliber, as their metabolic demand is greater. The caliber of these pathways is equal in all neuroaxis. ${ }^{28}$ Corticospinal and proprioceptive pathways are more susceptible to damage when compressive forces are equally distributed over the medulla, representing a 
selective vulnerability to hypoxic and metabolic phenomena, and this damage can extend for a long distance. ${ }^{28}$

Coordination disorders were present in 20 (62.5\%) patients, with axial and appendicular involvement in 6 (18.75\%) and 14 (43.75\%) patients, respectively. Caetano de Barros et al, when analyzing "pure forms of Arnold-Chiari malformation," found that $100 \%$ of patients had cerebellar disorders. ${ }^{11}$ They concluded that cerebellar dysfunction in association with 9th and 10th cranial nerve palsy were typical findings in their patients. ${ }^{10}$ Silva described cerebellar dysfunction in $50.3 \%$ of their patients, and gait disorders were slightly more common than appendicular disorders. ${ }^{12}$ Axial disorders have been attributed to flocculonodular lobe dysfunction, whereas appendicular ataxia has been related to spinocerebellar pathway dysfunction, during its pathway through CVJ. ${ }^{29-31}$ Multiplicity of pathways and connections makes cerebellar function less vulnerable to damage in CVJ abnormalities.

In the present series, involvement of the 9th and 10th cranial nerves was documented in almost half of the patients. As previously mentioned, Caetano de Barros et al considered these nerves dysfunctions typical of patients with CM I. ${ }^{11}$ Silva reported involvement of these nerves in $63.4 \%$ of their patients. ${ }^{12}$ The frequency of other cranial nerve involvement was lower. According to the authors this might have happened due to the analysis being restricted to patients with isolated CM I, while patients with important ventral compression at CVJ were excluded. In CM I, the primary compression is predominant at the posterior region of CVJ.

\section{Conclusion}

Deep tendinous reflexes and proprioception disorders were the main neurologic features in a series of symptomatic surgical CM I patients.

\section{References}

1 Alden TD, Ojemann JG, Park TS. Surgical treatment of Chiari I malformation: indications and approaches. Neurosurg Focus $2001 ; 11(01):$ E2

2 Lazareff JA, Galarza M, Gravori T, Spinks TJ. Tonsillectomy without craniectomy for the management of infantile Chiari I malformation. J Neurosurg 2002;97(05):1018-1022

3 Bejjani GK. Definition of the adult Chiari malformation: a brief historical overview. Neurosurg Focus 2001;11(01):E1

4 Bejjani GK, Cockerham KP, Rothfus WE, Maroon JC, Maddock M. Treatment of failed Adult Chiari: Malformation decompression with CSF drainage: observations in six patients. Acta Neurochir (Wien) 2001 Feb;145(02):107-116; discussion 116

5 Wan MJ, Nomura $\mathrm{H}$, Tator $\mathrm{CH}$. Conversion to symptomatic Chiari I malformation after minor head or neck trauma. Neurosurgery 2008;63(04):748-753, discussion 753

6 Dyste GN, Menezes AH, VanGilder JC. Symptomatic Chiari malformations. An analysis of presentation, management, and long-term outcome. J Neurosurg 1989;71(02):159-168

7 Oakes W, Gaskill S. Chiari Malformation, hydromyelia, and syringomyelia. In Wilkins R, Rengachary S (eds): Neurosurgery. New York: McGraw-Hill; 1985:2102-2124

8 Sahuquillo J, Rubio E, Poca MA, Rovira A, Rodriguez-Baeza A, Cervera C. Posterior fossa reconstruction: a surgical technique for the treatment of Chiari I malformation and Chiari I/syringomyelia complex-preliminary results and magnetic resonance imaging quantitative assessment of hindbrain migration. Neurosurgery 1994;35(05):874-884, discussion 884-885

9 Alzate JC, Kothbauer KF, Jallo GI, Epstein FJ. Treatment of Chiari I malformation in patients with and without syringomyelia: a consecutive series of 66 cases. Neurosurg Focus 2001;11(01):E3

10 Richard G. Everson, MD, Langston T. Holly, MD, and Ulrich Batzdorf, MD.Chiari 1 Malformation in the Adult: Part I. Contemporary Neurosurgery 2017;39:4

11 Caetano de Barros M, Farias W, Ataíde L, Lins S. Basilar impression and Arnold-Chiari malformation. A study of 66 cases. J Neurol Neurosurg Psychiatry 1968;31(06):596-605

12 Silva J. Impressão basilar: Malformações Occipitocervicais [Basilar impression: Occipitocervical Malformations]. Recife: Editora Universitária-UFPE; 2003. Portuguese

13 McGirt MJ, Nimjee SM, Floyd J, Bulsara KR, George TM. Correlation of cerebrospinal fluid flow dynamics and headache in Chiari I malformation. Neurosurgery 2005;56(04):716-721, discussion 716-721

14 Matsumoto T, Symon L. Surgical management of syringomyeliacurrent results. Surg Neurol 1989;32(04):258-265

15 Saez RJ, Onofrio BM, Yanagihara T. Experience with Arnold-Chiari malformation, 1960 to 1970. J Neurosurg 1976;45(04):416-422

16 Mauer UM, Gottschalk A, Mueller C, Weselek L, Kunz U, Schulz C. Standard and cardiac-gated phase-contrast magnetic resonance imaging in the clinical course of patients with Chiari malformation Type I. Neurosurg Focus 2011;31(03):E5

17 Gilman S. Joint position sense and vibration sense: anatomical organisation and assessment. J Neurol Neurosurg Psychiatry 2002;73(05):473-477

18 Calne DB, Pallis CA. Vibratory sense: a critical review. Brain 1966; 89(04):723-746

19 Netsky MG. Syringomyelia; a clinicopathologic study. AMA Arch Neurol Psychiatry 1953;70(06):741-777

20 Doppman JL, Girton M, Popovsky MA. Acute occlusion of the posterior spinal vein. Experimental study in monkeys. J Neurosurg 1979;51(02):201-205

21 Henderson FC, Crockard HA, Stevens JM. Spinal cord oedema due to venous stasis. Neuroradiology 1993;35(04):312-315

22 Taylor AR, Byrnes DP. Foramen magnum and high cervical cord compression. Brain 1974;97(03):473-480

23 Schmidt BJ. Subacute delayed ascending myelopathy after low spine injury: case report and evidence of a vascular mechanism. Spinal Cord 2006;44(05):322-325

24 Levine DN. The pathogenesis of syringomyelia associated with lesions at the foramen magnum: a critical review of existing theories and proposal of a new hypothesis. J Neurol Sci 2004;220(1-2):3-21

25 Tseng J-S, Lee Y-C, Pan H-C, Chang M-H. Motor neuron disease-like syndrome secondary to trapped fourth ventricle and obstruction of cerebrospinal fluid pathway. Clin Neurol Neurosurg 2007;109 (04):383-387

26 Ravaglia S, Bogdanov EI, Pichiecchio A, Bergamaschi R, Moglia A, Mikhaylov IM. Pathogenetic role of myelitis for syringomyelia. Clin Neurol Neurosurg 2007;109(06):541-546

27 Silva J, Silva E, Nóbrega P. Pyramidal liberation syndrome as clinical expression of basilar impression: report of 2 operated cases. Arq bras neurocir 1990; 9:161-7

28 Kahn EA. The role of the dentate ligaments in spinal cord compression and the syndrome of lateral sclerosis. J Neurosurg 1947;4(03):191-199

29 Canelas HM, Tenuto RA, Zaclis J, Cruz OR. [Occipito-cervical deformities; 20 new cases]. Arq Neuropsiquiatr 1956;14(01):1-27

30 Layzer RB. Myeloneuropathy after prolonged exposure to nitrous oxide. Lancet 1978;2(8102):1227-1230

31 Prabhakar NR, Pieramici SF, Premkumar DR, Kumar GK, Kalaria RN. Activation of nitric oxide synthase gene expression by hypoxia in central and peripheral neurons. Brain Res Mol Brain Res 1996;43(1-2):341-346 